\title{
Schools Distribution Planning using GIS in Jeddah City
}

\author{
Mazloh Al-Enazi \\ Arab Academy for Science, \\ Technology and Maritime \\ Transport \\ Alexandria, Egypt.
}

\author{
Saleh Mesbah \\ Arab Academy for Science, \\ Technology and Maritime \\ Transport \\ Alexandria, Egypt.
}

\author{
Amani Anwar \\ Arab Academy for Science, \\ Technology and Maritime \\ Transport \\ Alexandria, Egypt.
}

\begin{abstract}
Geographical Information Systems (GIS) are used today to provide advanced analysis tools and complete data packages for analyzing services distribution and demographic information. These tools can help planners in taking important decision such as choosing schools locations, and identifying best schools new locations. The aim of this paper is to use GIS functions (overlay analysis, and buffer) in evaluating spatial distribution of schools. The study area in this study is a residential area of Jeddah city, Saudi Arabia. A geo-database is designed that includes land use of Jeddah, and schools located in Jeddah city. Several GIS functions are used in this paper using ArcGIS 10.2. The results are utilized in evaluating spatial distribution of schools, which can help planner in managing the distribution of the future schools at Jeddah city.
\end{abstract}

\section{Keywords}

GIS, schools, Jeddah city

\section{INTRODUCTION}

Geographic information system (GIS) is rapidly being developed and applied in a no-limit list of applications. Planning in particular, have greatly benefited from this effective and efficient technology [1]. GIS are used today in several planning applications including land use planning, health care planning, and transportation planning. Evaluation of services distribution is considered as one of the planning fields that could benefit from using this novel technology. Planners are faced today with many issues that can be better handled with GIS. These include constructing demographic, and finding the best locations for new services, in correlation congestion points [2]. Service analysis, visualization, traffic flow environmental impact and decision making from the point of GIS view. Therefore it is necessary to provide decision-makers with up to-date information in an easily understandable form.

The analysis on transport infrastructure expansion has in Jeddah considered four categories of transportation infrastructure: highways, primary roads and secondary roads, and services distribution. The studies indicate that Jeddah underwent tremendous transportation infrastructure expansion from 1964 to 2007 [3]. Transportation infrastructure increased rapidly from $136 \mathrm{~km}$ to $435 \mathrm{~km}$ in 1970 to 1980 , with a change of $69 \%$ and an annual growth of $6.9 \%$ respectively. Most of the transportation infrastructure in Jeddah was constructed during this period [3].

The main objectives of this paper are:

- Demonstrating the importance of GIS in the analysis of schools distribution

- Using different types of analysis tools;

- $\quad$ Evaluating spatial distribution of schools.

\section{LITERATURE REVIEW}

GIS technology is appropriate for a variety of usages including resource management, land surveying, and traffic planning. Traffic uses GIS technology to solve problems, find solutions for traffic congestion, delivering better services distribution, and making good decisions. In addition, GIS technology has been implemented in service management for displaying large volumes of diverse data pertinent to various local and regional planning activities [4].

Service inequalities are aggravating due to increased growth rate, population, modernization and improved lifestyle. Not only do service inequalities bottlenecks increase due to these factors but weather conditions also intensify the situation [5].

The simplest GIS tools that can be used for service distribution GIS application is related to displaying and querying spatial and attribute data. For example, ArcGIS software has several functions that can be used for data query and display. This software can display attributes in relation to points, lines or polygons, otherwise known as thematic mapping [6].

A number of studies have used GIS in order to examine spatial inequalities of services using accessibility measures [7, 8, and 9]. Such measures typically involve counting the number of services contained within census tract boundaries [10], or reporting the number of facilities inside a given Euclidean or travel-time distance of demand points.

Also [11] demonstrate the importance of Geographic Information System (GIS) as a support tool in developing policies for the organization, management and promotion of transport efficiency in Almada, a Portuguese city.

\section{STUDY AREA: JEDDAH CITY}

Jeddah city is the second largest city in Saudi Arabia. Jeddah city has witnessed a remarkably rapid urban growth rate during the past four decades. Jeddah has witnessed a dramatic increase in population primarily due to out-migration from villages and from suburbs to the city by individuals in search of jobs and better living [12]. With population and economic development keeping pace, the pressure on the traffic system has been tremendous. Up until now the road network is not stable and has been witnessing changes or amendments in lanes and roads, which put pressure on vehicle users because they need to constantly find easier ways to get to their destinations.

The strength of the economy and the growth in the population are increasingly straining the city's transportation system. Jeddah is car-dominated, with residents using private automobiles for $93 \%$ of their travel [12]. The challenges of accelerated urban expansion, population growth and traffic congestion are currently the main issues in Jeddah, and its local government faces many challenges in managing its urban growth, land use and transportation. Land use in Jeddah went through remarkable changes during the period of 1964 to 
2014. Although all land uses changed from 1964 to 2014, five significant land use classes have rapidly and actively changed: residential, commercial, industrial, informal settlements and public places. Residential development in Jeddah city has dramatically, notably catalyzed by the constructed transportation infrastructure, the new airport location and the government's development policies, such as land grants and interest-free loans [13].

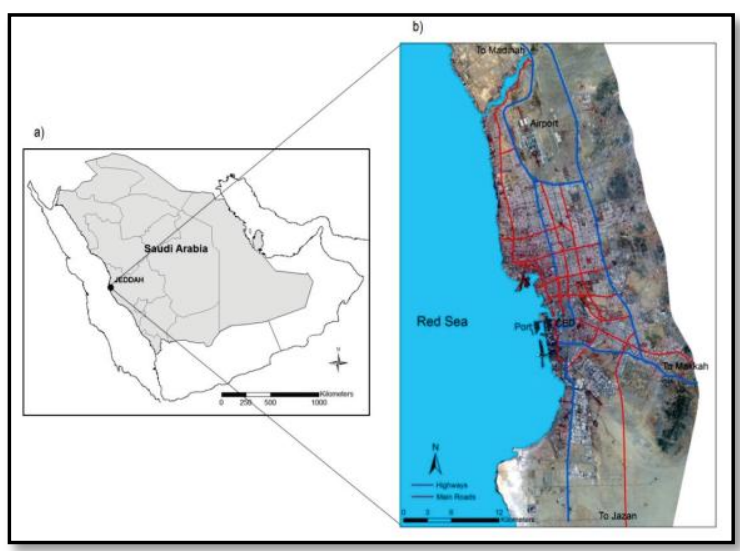

Figure 1: A general location map of the study area [13

\section{GEO-DATABASE DESIGN}

As a component of the applied stage, a portion of the strides utilized "information outline designs". Information plan examples are generally reoccurring connections among information components that show up so often, it depends on their presence for translation of information. The results of an applied configuration stage in database outline will complete an exchange about what is the purpose and significance of the information that is expected to infer data, putting that data in the setting of confirmation and knowledge.

Identifying the thematic layers which are needed for the application is the first step, then, deeply defines each of these layers in more details. The characterization of these layers will result in geo-database which takes different types of data elements, such as feature classes, tables, relationship classes, raster datasets, subtypes, topologies, domains, and so on. As shown in Table (1).

Table 1: Geo-Databases Themes

\begin{tabular}{|c|c|l|c|c|}
\hline $\begin{array}{c}\text { layer } \\
\text { Name }\end{array}$ & $\begin{array}{c}\text { Layer } \\
\text { description }\end{array}$ & Feature type & Source & Resolution \\
\hline $\begin{array}{c}\text { Land } \\
\text { use }\end{array}$ & $\begin{array}{c}\text { Building's } \\
\text { and blocks }\end{array}$ & $\begin{array}{l}\text { Vector/polyg } \\
\text { on }\end{array}$ & $\begin{array}{c}\text { Esri } \\
\text { Imagery }\end{array}$ & $60 \mathrm{~cm}$ \\
\hline Roads & $\begin{array}{c}\text { All Road } \\
\text { network }\end{array}$ & Vector/line & $\begin{array}{c}\text { Esri } \\
\text { Imagery }\end{array}$ & $60 \mathrm{~cm}$ \\
\hline $\begin{array}{c}\text { School } \\
\text { s }\end{array}$ & $\begin{array}{c}\text { All school } \\
\text { type }\end{array}$ & Vector/point & $\begin{array}{c}\text { Esri } \\
\text { Imagery }\end{array}$ & $60 \mathrm{~cm}$ \\
\hline
\end{tabular}

The purpose of this paper is to use GIS application for evaluating spatial distribution of schools at Jeddah city. The application covers a buffer area for the distribution of schools according to the areas served by those schools. In order to use this application, several data sets were captured and built using ArcGIS software, as the following:

a- Points data one of the prime objectives of this application is to define schools based on locations. Accordingly, a survey was made on a sample of schools; Figure 2 shows the distribution of those points. Their locations were converted in the GIS as point features with a city district resolution. In addition, the exact location of schools centers are modeled in the GIS as points features.

b- Polygon and line data. In addition to services features, the present application created polygon features showing city district boundaries; Figure 3 shows land use include residential areas as parcels as well as line features showing city road network; Figure 4 shows road network. These two basic GIS features were used with point data to define and model the schools area of Jeddah city. For each of these features the relevant attributes were linked at the feature attribute table.

The data for application of Arc GIS tool box was available for different analysis. Storing GIS data in the geo-database enables users to take advantage of its advanced data modeling properties.

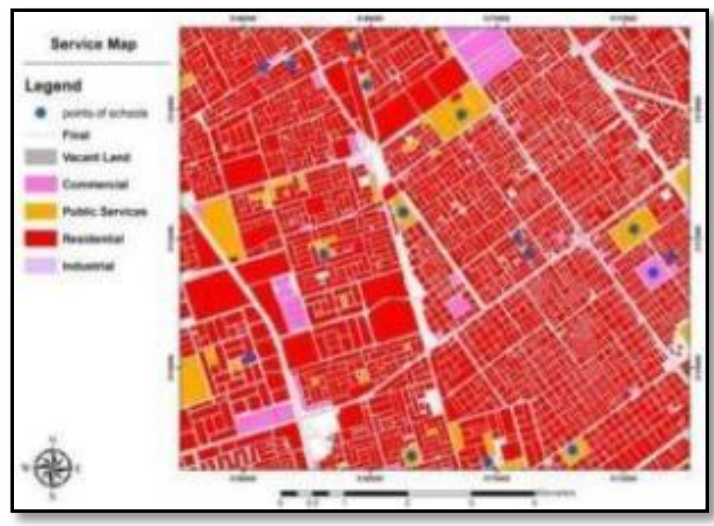

Figure (2) Distributions of Schools in Jeddah city

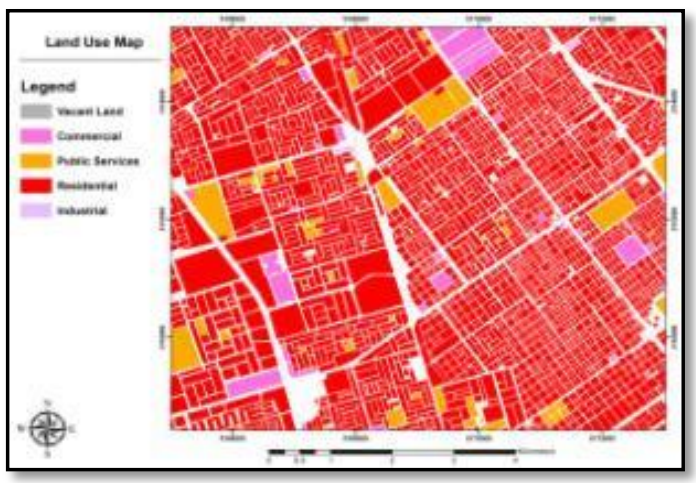

Figure (3) Land use of Jeddah

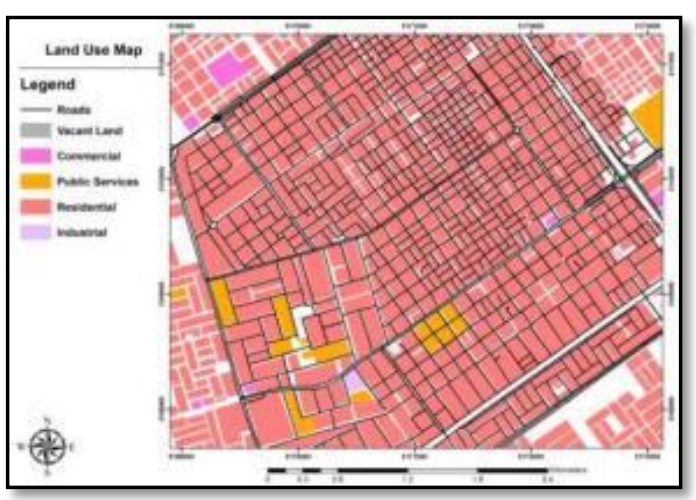

Figure (4) Road network in Jeddah city 


\section{ANALYSIS}

\subsection{Bufferanalysis}

The proper approach followed in analyzing added capacity projects is to examine the project's effects upon schools distribution within residential areas based on a census data. Here in this paper it includes densely populated residential neighborhoods who study in the school stage as shown in Table 2 and figure 5.

Calculating the schools distributions that could result from implementing the schools within the impact area (buffer) then tests the school's impacts. Using GIS, buffers are created around each school representing the service area. In GIS, the links located inside the schools services area (buffer) can be captured. This process involves incorporating the roads, and schools allocations data into the attribute file, which is transferred from GIS to a data base application to undertake the evaluations required.

The benefits of GIS in this process is that it allowed for generating the buffers required for each school and identification of the different roads located inside the impact area.

Table 2: Population density of selected residential areas [14]

\begin{tabular}{|c|c|}
\hline Residential name & $\begin{array}{c}\text { Population density at } \\
\text { school stage }\end{array}$ \\
\hline Mohamdea & 12213.2 \\
\hline Al Zaharaa & 17082 \\
\hline Rawda & 23120 \\
\hline Al Salama & 31672 \\
\hline Al Rabwa & 60206 \\
\hline Al Safa & 85944 \\
\hline
\end{tabular}

Figure 5:Population density at school stage

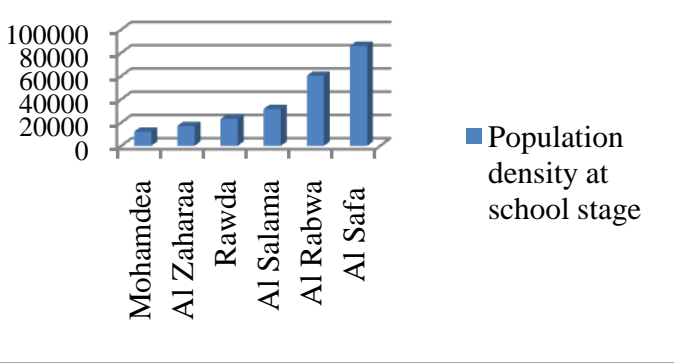

\subsection{Measuring Orientation And Direction Of Service Location}

Measuring distribution schools help planners in abstracting the spatial trends in the distribution of school centers. GIS spatial statistic functions can be used to measure whether-and to what extent- the distribution of features crates a pattern. The resulted direction of pattern can be used for several purposes, for example in this paper it examines the inequalities of the services distribution in Jeddah city.

GIS spatial statistic tools can define the direction and orientation of points, polygons and lines features.

For the presented application, point's features showing schools centers location are selected and used within ArcGIS spatial statistical tools to define the orientation of services centers in Jeddah city. The result of this type of analysis is presented in the form of an ellipse shape. It is produced by calculating standard distance in the $\mathrm{x}$ and $\mathrm{y}$ directions and by defining the axes of an ellipse encompassing the distribution of features.

The ellipse is referred to as the standard deviation ellipse which allows the analyst to see if the distribution of features is elongated and hence has a particular orientation (ibid).

The standard deviation ellipse measures the standard deviation of the features from the mean center separately for the $\mathrm{x}$-coordinates and the y-coordinates. The length of the ellipse axes are calculated in the east-west (x-axis) and northsouth (y-axis) directions in distance unites (meters). Since the standard deviation is measured in each direction from the mean center, the total length of each axis is twice its standard deviation (ibid).

The presented study has calculated the standard deviation ellipse for schools center group. The resulted ellipse for every school center group is shown in Figure 6. Based on this result can easily identify the pattern and trends of all school centers in Jeddah city. It is clear that orientation of services in Jeddah city is bad distributions.

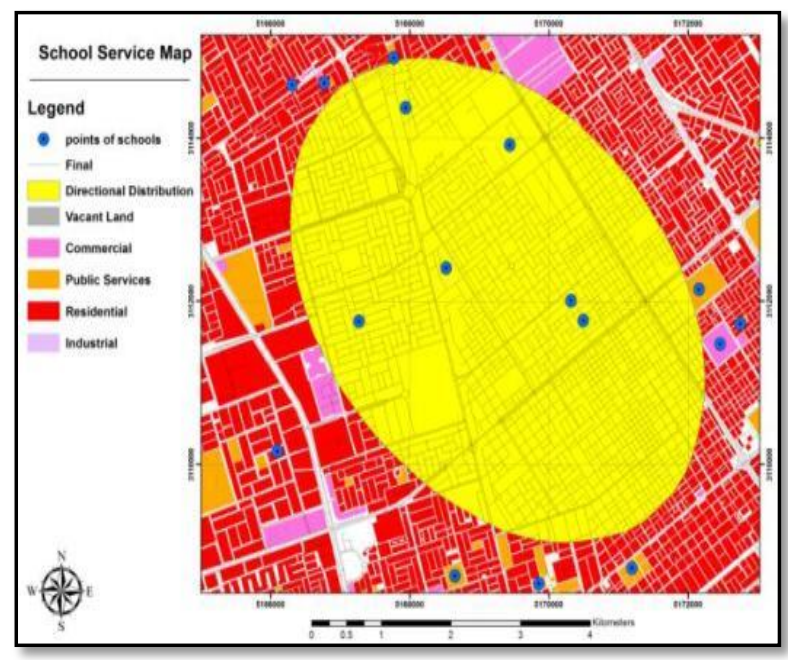

Figure (6) Standard Deviations ellipse shows directional distributions for the Schools in Jeddah city

\section{RESULTS}

This part of the paper discusses how GIS can be applied to evaluate the distribution of the existing schools. There are several GIS-based techniques to be used for preparing policies in this respect as shown in Figure 7.

Looking at the various types of GIS-based service area definition techniques, the presented paper has selected the buffer method. Accordingly, the first step to produce this output was to plot and map the locations of schools that were interviewed in the course of this study. Using city-district shape file as a reference data and address table of schools, the application produced point features describing the spatial distribution of schools in Jeddah city.

This output shows the dissemination of the schools area of the selected residential areas. It is evident that there are some parts of the city (Al-Rabwah, and Al-Salamah) which produce remarkable schools to this center, but on the other hand $\mathrm{Al}$ Safa residential area didn't cover with any school service although it is the highest populated area from the selected. Also Al Rawda residential area covers only with 3 schools, at 
the same time Mohamdea residential area covers with 7 schools although it is less populated than Rwada residential area. This output forms the primary schools area which can be used by service planners to define the parts of the city providing a larger amount of schools to this center. Also it advises planners concerning the locations where no schools are produced, and, accordingly, to focus on these locations and try to expand the school services to cover such less attracted areas. For these districts such as Al-Safa, and AlRawda are located within the less services bands. Therefore, planners should approach these districts more closely and introduce their school services to people living in such areas.

The results of the created GIS application are considered as valuable tools for increasing the efficiency of school service management and for evaluating the performance dynamics of school services.

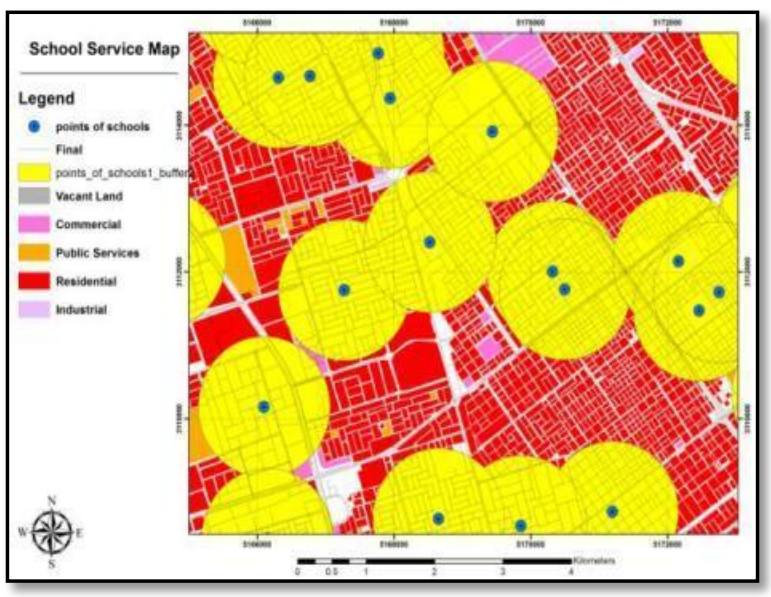

Figure (7) Schools distributions within buffer $750 \mathrm{~m}$

\section{CONCLUSION}

Methodology for school services spatial distribution in the paper includes the various steps and use of GIS technology. It integrates the geo-database, buffer and overlay tools. The priority results are utilized in evaluating spatial distribution of schools. Results obtained from these tools compare alternate improvement strategies, and solutions thus giving the best possible solution.

ArcGIS is a collaborative that allows using, creating, and sharing maps, apps, and data, including authoritative base maps. Finally, a school service area investigation has been performed based on GIS buffer analysis technique and by using GIS overlay analysis function it could define the inequalities services distribution. This methodology could help planners in managing the distribution of the future services at all parts of Jeddah city.

The results provide significant information on the spatial distribution of schools with the relation of population density in different sites of Jeddah city.

Further research should employ more spatial statistical analysis and dynamic modeling in order to further illustration of this mutual relationship. Additionally, inclusion of the concept of Spatial Decision Support Systems (SDSS) based around GIS technology must be considered in future analyses.

\section{REFERENCES}

[1] Antenucci J., Brown K., Croswell P. Kevany M., with Archer H., (1991) GeographicInformation System: A Guide to the Technology.

[2] Olson, D, Chae, B, and Sheu, C (2005) ' Issues in multinational ERP implementation' Int. J. of Services and Operations Management 2005 - Vol. 1, No.1 pp. 7 21.

[3] Al Ahmadi, K, See, L.M., Heppenstall, A.J., and Hogg, J. (2009). Calibration of a fuzzy cellular automata model of urban dynamics in SaudiArabia. Ecological Complexity, 6(2), 80-101.

[4] Cheng, E, and Ling Yu, H, (2007) ' A GIS approach to shopping mall location selection Building and Environment' Vol. 42, pp. 884-892.

[5] Gang Cheng, Qingyun Du, Hongli Ma, (2008) "The Design and Implementation of Rules Based Knowledge Base for Transportation", IEEE International Conference on Computer Science and Software Engineering, Vol. 3, pp $1035-1038$.

[6] Grimshaw D., (2000) Bringing Geographical Information Systems into Business, Wiley, New York.

[7] Langford, M. (2007). Rapid facilitation of dasymetricbased population interpolation by means of raster pixel maps. Computers Environment and Urban Systems, Vol. 31, pp. 19-32.

[8] McLafferty, S. L., \& Grady, S. (2004). Prenatal care need and access: A GIS analysis. Journal of Medical Systems, Vol. 28, No.3, pp. 321-333.

[9] Phillips, R. L., Kinman, E. L., \&Lindbloom, E. J. (2000). Using Geographic Information Systems to Understand Health Care Access.Archives Family Medicine, Vol. 9, pp. 971-978.

[10] Lin, S. J. (2004). Access to community pharmacies by the elderly in Illinois: A geographic information systems analysis. Journal of Medical Systems, Vol.28, No.3, pp. 301-309.

[11] Leite, and FERREIRA (2011).Application of GIS in Public Transportation.Proceedings of 7VCT, Lisbon, Portugal- pp.439-446.

[12] IBI, G. (2007). Jeddah Public Transportation Study.Ministry of Transportation, Saudi Arabia.

[13] Aljoufie, M., Zuidgeest, M.H.P., Brussel, M.J.G., and van Maarseveen, M.F.A.M. (2011). Urban growth and transport understanding the spatial temporal relationship, in: Pratelli, A.,Brebbia, C.A. (Eds.), Urban transport XVII : urban transport and the environment in the 21st Century. WIT press, Southampton, pp. 315-328.

[14] Jeddah Municipality (2004). Jeddah Structure Plan, Jeddah Municipality, Saudi Arabia. 